\title{
N-Propionylated Polysialic Acid Antibody
}

National Cancer Institute

\section{Source}

National Cancer Institute. N-Propionylated Polysialic Acid Antibody. NCI Thesaurus. Code C118196.

Any immunog lobulin that recognizes N-propionylated polysialic acid (NPrPSA). 